\title{
Erratum to: Detox Fashion
}

\author{
Subramanian Senthilkannan Muthu
}

\section{Erratum to:}

\section{S.S. Muthu (ed.), Detox Fashion,}

\section{Textile Science and Clothing Technology,} https://doi.org/10.1007/978-981-10-4777-0

In the original version of the book, the Chapters "Detoxifying Luxury and Fashion Industry: Case of Market Driving Brands" and "Integrating Sustainable Strategies in Fashion Design by Detox 2020 Plan - Case Studies from Different Brands" have been replaced with new Chapters "Environmental Issues in Textiles: Global Regulations, Restrictions and Research" and "Making the Change: The Consumer Adoption of Sustainable Fashion". 